\title{
The Effect of Stretching and Elastic Band Exercises Knee Space Distance and Plantar Pressure Distribution during Walking in Young Individuals with Genu Varum
}

\author{
So-Ra Park • Hyo-Lyun Ro $\cdot$ Seung Namkoong ${ }^{\dagger}$
}

Dept. of Physical Therapy, Kangwon National University

Received: November 18, 2016 / Revised: November 22, 2016 / Accepted: January 12, 2017

(C) 2017 J Korean Soc Phys Med

\section{| Abstract |}

PURPOSE: The purpose of this study was to investigate the effects of stretching and elastic band exercise on the knee space distance and plantar pressure distribution in people with genu varum.

METHODS: The subjects of this study were students of a college who had genu varum of 14 subjects. The subjects were randomly divided into two groups as a stretching group $(\mathrm{n}=7$, 4 males and 3 females, age: $20.14 \pm 2.54$ years, height: $167.1 \pm 9.78 \mathrm{~cm}$, weight: $58.6 \pm 10.13 \mathrm{~kg}$ ) and a Thera-band group ( $\mathrm{n}=7,5$ males and 2 females, age: $19.85 \pm 2.04$ years, height: $166.5 \pm 5.82 \mathrm{~cm}$, weight: $54.2 \pm 5.59 \mathrm{~kg}$ ). The stretching and the There-band exercises were performed three times per a week, for four weeks. We measured changes in plantar pressure during walking, using a Gait Analyzer and distance of both knees at pre and post-intervention.

RESULTS: These results suggest that the space distance of both knees showed differences before and after the intervention. The plantar pressure distribution was no changes in

†Corresponding Author : seungnk@kangwon.ac.kr

This is an Open Access article distributed under the terms of the Creative Commons Attribution Non-Commercial License (http://creativecommons.org/licenses/by-nc/3.0) which permits unrestricted non-commercial use, distribution, and reproduction in any medium, provided the original work is properly cited. both groups before and after the intervention except for the left foot in a stretching group.

CONCLUSION: As a result, the space distance of knees in both groups was significantly reduced. These result suggested that the Thera-band and stretching exercises were effective ways in alleviating genu varum.

Key Words: Genu varum, Stretching, Thera-band

\section{INTRODUCTION}

Genu varum indicates a type of deformity marked by the laterally bowed knee joints and the distant side of the shinbones and splint bones that were inwardly curved. Genu varum deformity, involves a varus angulation of the tibia in which the knees are separated more than the feet during standing (Gheluwe et al., 2005). It is basically caused by instability of the joints or ligaments, abnormality of the bones, degenerative joint deformity, and pain. Joint deformity is usually caused by static factors such as inherent congenitalness or development deformity and abnormal stress (Jacquelin and Judith, 2012). The legs with genu varum may be caused by deformity either in the spine or in the lower limbs and in consequent induce secondary and tertiary problems to have effects on the physique and 
balance, which makes the deformity (Kwon, 2002).

Genu varum is reported to occur 15 to $20 \%$ in the whole population. While genu valgum, or inwardly-bent knees, is generally found in Western Europeans, genu varum occupies more than $90 \%$ in Korean cases (Moon et al., 1976), a phenomenon that may be caused by wearing high heels and life habit such as sedentary lifestyle. Genu varum induces gait difficulty and aesthetical problems, causing chronic fatigue, spinal deformity, aging, backache, and neuralgia (Kwon, 2002). When compared to the normal knees, the knees with genu varum may increase postural swaying and cause postural imbalance (Chang, 2010; Samaei et al., 2012).

It has also been claimed that genu varum deformity would tend to cause an increase in subtalar pronation moment during the contact and also in the propulsion phases of walking, while a genu valgum deformity may cause some increase in subtalar pronation moment during the contact phase and an increase in subtalar supination moment during the early propulsive phase (Karen et al., 2005). The specific effects of genu varum deformities on foot function. If genu varum deformities alter the nature of the ground reaction force (GRF), then this would significantly affect the mechanical function of the foot (Gheluwe et al., 2005).

Genu varum can be corrected either by non-surgical or surgical techniques. Non-surgical therapies include stretching, elastic band exercise, sling exercise, walking traction, muscle resistance exercise, chiropractic, chuna, and wearing corrective apparatus (Kang, 2008; Kim and Lee, 2010; Oh, 2011; Han, 2009). Stretching and elastic band exercise among the non-surgical treatments are interventions that are easy to be accessed.

Stretching is reported to be effective on prevention of musculoskeletal damage (Wilkinson, 1992; Smith, 1994; Kim et al., 2013), to increase the connective tissues around the joints (Jacobson and Speechley, 1990), and to be helpful in improving motor performance and in rehabilitating musculoskeletal system (Anderson and Burke, 1991; Beaulieu, 1981; Worrell et al., 1994). Anyone can easily do stretching regardless of time and space because it does not require special skills nor physical conditions (Hong, 2009). Elastic bands are rubber bands that are used as an instrument of medical rehabilitation; they are convenient to use, economical, and widely used (Ham, 2000). The bands are appropriate for strengthening muscles because they can provide wide-ranged loads, being widely used for rehabilitation treatment of sports injury or disability (Yamamoto, 2000). The elastic bands stimulate proprioceptive sensibility in the joints and the muscles, which delivers information of location and movement of the joints to the brain, contributing to maintaining proper postures and improving basic physical fitness (Petterson et al., 2011; Kim et al., 2016) According to some reports, combination of stretching, elastic band, and sling exercises reduced the distance of both knees while regular elastic band exercise decreased the distance in those who had deformed knees by genu varum (Kang et al., 2009; Han et al., 2011). However, there have been few domestic reports on relations of such exercises to physical balance in people with genu varum, a type of knee deformity common in Koreans.

In this study investigated effects of stretching and elastic band exercise on the knee space distance and plantar pressure distribution in people with genu varum.

\section{METHODS}

\section{Subject and Methods}

This study was conducted as a single blind study. The study participants did not know about the group they joined. The subjects were randomly selected by drawing lots and divided into two groups as a stretching group and a Thera-band group.

The subjects of this study were students of a college who had genu varum. Based on the research of Moon et al. (1976), those who were at least Grade II in the distance of both knees (2.5 $\mathrm{cm}$ and more) and who did not have other medical, neurological, and musculoskeletal disorders 
were selected to be the subjects of this study (Table 1). We sufficiently explained the purpose and the methods of this study to the students, and those who voluntarily participated in the experiment were selected to be the subjects.

Table 1. Grade of Knee space width

\begin{tabular}{cc}
\hline Grade & Knee space width \\
\hline Grade I & $2.5 \mathrm{~cm}$ less than \\
Grade II & $2.5 \mathrm{~cm} \sim 5 \mathrm{~cm}$ \\
Grade III & $5 \mathrm{~cm} \sim 7.5 \mathrm{~cm}$ \\
Grade IV & $7.5 \mathrm{~cm}$ more than \\
\hline
\end{tabular}

While the research of $\mathrm{Yu}$ and Kim (2015) performed a type of complex exercise of stretching mixed with elastic band exercise, we in this study divided the subjects into a group of stretching and a group of elastic band (Thera-band) exercise in order to identify more effective intervention. Stretching exercises were performed mainly hip adductor and extension. It was located on the thigh. The elastic band exercises were organized mainly to a hip joint motion for the strengthening of muscle.

A total of 14 subjects were randomly divided into a stretching group ( $\mathrm{n}=7)$ and a Thera-band group $(\mathrm{n}=7)$. The stretching group consisted of four males and three females $(20.14 \pm 2.54$ years old, $167.1 \pm 9.78 \mathrm{~cm}$ in height, and $58.6 \pm 10.13 \mathrm{~kg}$ in weight), while the Thera-band group consisted of five males and two females $(19.85 \pm 2.04$ years old, $166.5 \pm 5.82 \mathrm{~cm}$ in height, and $54.2 \pm 5.59 \mathrm{~kg}$ in weight). The stretching and the There-band exercises were performed three times per week, for four weeks.

\section{Exercise Programs}

\section{1) Stretching}

We adjusted and supplemented the stretching exercise program provided by Kang et al. (2009) to be used in this study. The program took 60 minutes consisting of ten-minute warm-up, forty-minute stretching, and ten-minute cool-down. The stretching focused on the hamstring and the adductor muscles. Each of the exercise method consisted of two one-minute sets for each leg and for both legs (Table 2).

\section{2) Thera-band exercise}

We adjusted and supplemented the Thera-band exercise programs provided by Han (2009) and Kwon (2013) to be used in this study. Our program required 60 minutes consisting of ten-minute warm-up, forty-minute Thera-band exercise, and ten-minute cool-down. The Thera-band exercise was for improving the external rotators and the extensors and for strengthening the quadriceps and the gluteus (Table 3). When a set required 15 times, each of the exercise methods consisted of three sets while the abductor/external rotator, the lunge, and the kick-back (except for the squat) consisted of 3 sets (Table 3 ).

\section{Measurement}

We measured changes the plantar pressure distribution during walking, using a Gait Analyzer (TS-GT001010, Korea) (Fig. 1). The plantar pressure distribution was measured during walking, the change occurs in the contact surface of the foot and the ground (Kim, 2006). While a subject was gaiting barefoot as he/she saw front, we measured the changes three times-before and after the program and after 45 days of the experiment. The average of the three measured values was used in statistical analysis.

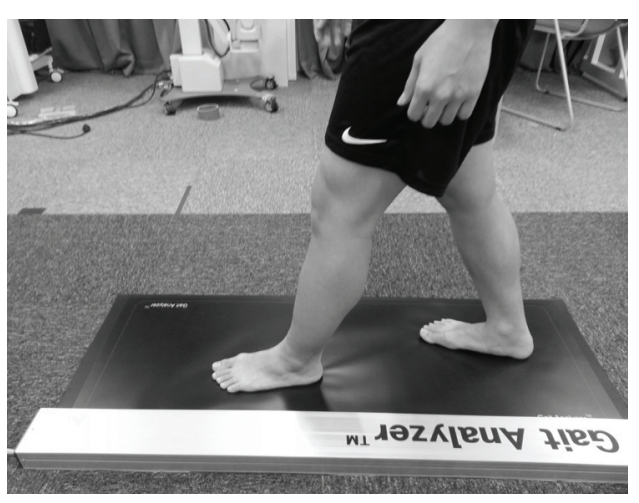

Fig. 1. Foot plantar pressure measurement. 
Table 2. Stretching exercise program

\begin{tabular}{|c|c|c|}
\hline Exercise & Method & Time/Set \\
\hline Warm up & Joint rotation exercise & $10 \mathrm{~min}$ \\
\hline Hamstring-1 & $\begin{array}{l}\text { In sitting position, flex one knee while other knee is extended. } \\
\text { Make the toe in extended part to face to the ceiling. }\end{array}$ & $\begin{array}{l}\text { each leg } \\
1 \mathrm{~min} / 2 \text { set }\end{array}$ \\
\hline Adductor-1 & $\begin{array}{l}\text { In sitting position, flex one knee while other knee is extended. } \\
\text { Make the toe in extended part to face to the front. }\end{array}$ & $\begin{array}{l}\text { each leg } \\
1 \mathrm{~min} / 2 \text { set }\end{array}$ \\
\hline Hamstring-2 & $\begin{array}{l}\text { Extend both knees in standing position and lift one leg on the desk } \\
\text { and slowly go down with maintaining straight back. }\end{array}$ & $\begin{array}{l}\text { each leg } \\
1 \mathrm{~min} / 2 \text { set }\end{array}$ \\
\hline Adductor-2 & $\begin{array}{l}\text { Face both sole of the feet and bring two heels of the foot to the } \\
\text { trunk as possible. And shift the trunk to both right and left. }\end{array}$ & $1 \mathrm{~min} / 2 \mathrm{set}$ \\
\hline Adductor-3 & $\begin{array}{l}\text { Face both sole of the feet and bring two heels of the foot to the } \\
\text { trunk as possible. And slowly bend your trunk. }\end{array}$ & $1 \mathrm{~min} / 2 \mathrm{set}$ \\
\hline Pelvic & $\begin{array}{l}\text { Put your two hands to the back in sitting position with straight } \\
\text { back. Flex both knees in } 90 \text { degrees. Fold the knee to make both } \\
\text { knees and toe face to the ground. }\end{array}$ & $1 \mathrm{~min} / 2 \mathrm{set}$ \\
\hline Hamstring-3 & Bend your trunk with both knee extended in sitting position. & $1 \mathrm{~min} / 2 \mathrm{set}$ \\
\hline Adductor-4 & $\begin{array}{l}\text { Make leg as "4"shape and push the flexed knee while other side of } \\
\text { the hand touch to the back area of the trunk. }\end{array}$ & $\begin{array}{l}\text { each leg } \\
1 \mathrm{~min} / 2 \text { set }\end{array}$ \\
\hline Hamstring-4 & Make leg as " 4 "shape and pull the flexed knee to the trunk. & $\begin{array}{l}\text { each leg } \\
1 \mathrm{~min} / 2 \text { set }\end{array}$ \\
\hline Adductor-5 & $\begin{array}{l}\text { Slowly bend your trunk between the anteriorly extended and } \\
\text { posteriorly flexed knee. }\end{array}$ & $\begin{array}{l}\text { each leg } \\
1 \mathrm{~min} / 2 \text { set }\end{array}$ \\
\hline Cool down & Joint rotation exercise & $10 \mathrm{~min}$ \\
\hline
\end{tabular}

Table 3. Thera-band resistance exercise program

\begin{tabular}{|c|c|c|}
\hline Exercise & Method & Time/Set \\
\hline Warm up & Joint rotation exercise & $10 \mathrm{~min}$ \\
\hline Squat & $\begin{array}{l}\text { Wind Thera-band around your thighs. Push the hip posteriorly and } \\
\text { slowly bend two knees. Do not bend your back. }\end{array}$ & $\begin{array}{l}15 \text { times/ } \\
3 \text { sets }\end{array}$ \\
\hline $\begin{array}{l}\text { Abductor/ } \\
\text { external rotator }\end{array}$ & $\begin{array}{l}\text { Lie in side line position with winding Thera-band around your } \\
\text { thighs. Widen the leg as describing a parabola with two toes } \\
\text { gathering together. }\end{array}$ & $\begin{array}{l}\text { each leg } \\
15 \text { times/ } \\
3 \text { sets }\end{array}$ \\
\hline Lunge & $\begin{array}{l}\text { During helper is holding Thera-band around your thigh, put one } \\
\text { feet anteriorly in } 90 \text { degrees while other feet is placed posteriorly } \\
\text { with plantar flexed. Slowly go down and return to the starting } \\
\text { position. }\end{array}$ & $\begin{array}{l}\text { each leg } \\
15 \text { times/ } \\
3 \text { sets }\end{array}$ \\
\hline Kick-back & $\begin{array}{l}\text { In quadriped position(both elbows and knees flexed), wind } \\
\text { Thera-band around hands and foot. Slowly raise the leg and } \\
\text { maintain balance. }\end{array}$ & $\begin{array}{l}\text { each leg } \\
15 \text { times/ } \\
3 \text { sets }\end{array}$ \\
\hline Cool down & Joint rotation exercise & $10 \mathrm{~min}$ \\
\hline
\end{tabular}




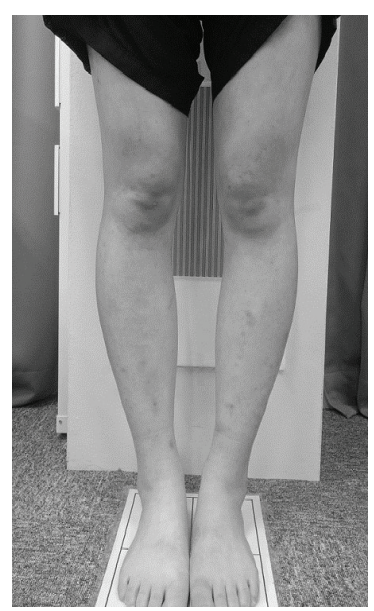

Fig. 2. Knees space distance measurement (provided by Han, 2009).

While measurement, at least two footprints had to be recognized; a case in which even one footprint was not recognized was excluded from the analysis.

We measured the knee space distance provided by Han (2009) to be used in this study. In this study, the measurement of knee space distance was performed by one person for reliability of measurement. When a barefoot subject stood in such a way that a board on which lines were drawn at intervals of $.5 \mathrm{~cm}$ was behind his/her knees and his/her feet were parallel to each other anatomically, we took a picture in front of the subject to measure the distance of medial epicondyles of the knees (Fig. 2).

\section{Statistical analysis}

The SPSS 20.0 was used to statistically process the data in this study. A Mann-Whitney test and a Wilcoxon signed ranks test as nonparametric tests were used. To compare the two groups Mean averages per group and standard deviation were calculated from all the data. The level of statistical significance was set at $p<.05$.

\section{RESULTS}

1. The homogeneity of subjects

The results of the Mann-Whitney test for group homogeneity showed no statistically significance differences, indicating that there was homogeneity in the stretching group and the Thera-band group. Therefore, the homogeneity of the two groups is secured (Table 4).

\section{Changes in knee space distance}

Changes in the knee space distance of the subjects with genu varum were investigated at pre- and post-intervention. According to analysis of the knee space distance intervened by the exercise program, the width showed statistically significant differences before and after the intervention $(p<.05)$ (Table 5). Therefore, the stretching and Thera-band exercise in this study reduced the space distance between knees.

Table 4. Homogeneity of stretching \& Thera-band exercises

\begin{tabular}{|c|c|c|c|c|c|}
\hline & Group & Mean Rank & Mann-Whitney U & Z & $p$ \\
\hline \multirow{2}{*}{ Pre } & Stretching $(n=7)$ & 7.14 & \multirow{2}{*}{22} & \multirow{2}{*}{-.32} & \multirow{2}{*}{.749} \\
\hline & Thera-band $(n=7)$ & 7.85 & & & \\
\hline \multirow{2}{*}{ Post } & Stretching & 6.57 & \multirow{2}{*}{18} & \multirow{2}{*}{-.83} & \multirow{2}{*}{.406} \\
\hline & Thera-band & 8.43 & & & \\
\hline
\end{tabular}

Table 5. Knees space width changed after stretching \& Thera-band exercises

\begin{tabular}{ccccc}
\hline Group & Pre & Post & Z & $p$ \\
\hline Stretch group $(\mathrm{n}=7)$ & $4.39 \pm 1.16 \mathrm{~A}$ & $3.43 \pm 1.0 \mathrm{~B}$ & -2.20 & .028 \\
Thera band group $(\mathrm{n}=7)$ & $4.71 \pm 1.42$ & $4.08 \pm 1.52$ & -2.37 & .018 \\
\hline
\end{tabular}


A.

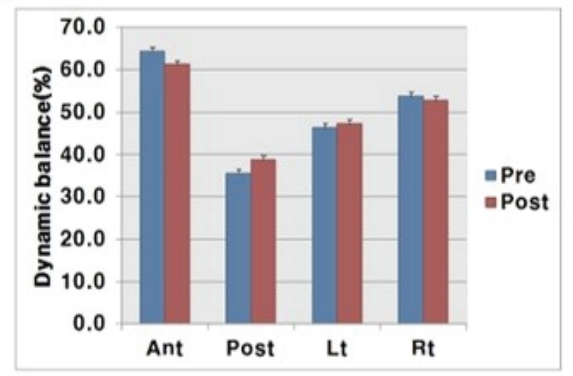

c.

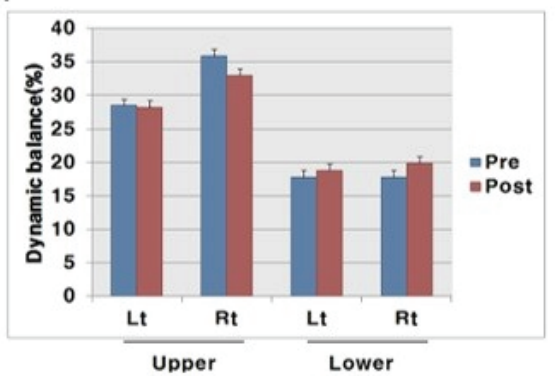

B.

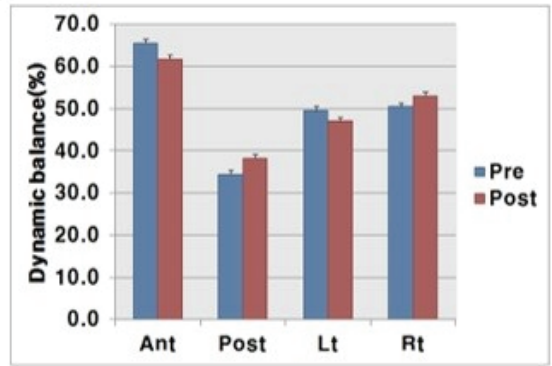

D.

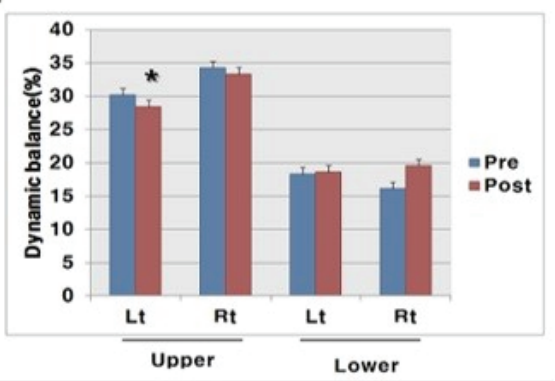

Fig. 3. Plantar pressure. A) and C) Thera-band resistance exercise group. B) and D) Stretching exercise group. Left bar: pre-treatment, Right bar: post-treatment, Ant: anterior, Post: posterior, Lt: Left, Rt: Right

\section{Changes in the plantar pressure distribution}

When changes in the plantar pressure distribution was investigated, there was no statistically significant changes in both groups before and after the intervention. In most of the subjects in both groups at pre- and post-intervention, the plantar pressure distribution was on their right feet rather than their left feet, and on the front part rather than the rear part of the feet (Fig. 3). Even on the front part of the foot, the plantar pressure distribution of foot was usually on the right side of the subjects. There were slight changes after the intervention; in both groups, the plantar pressure distribution of foot was slightly moved from the front to the rear part and from the right foot to the left foot. However, statistical significance was found only when the plantar pressure was reduced from the front part of the left foot (Fig. 3D).

\section{DISCUSSION}

The purpose of this study was to identify effects of stretching and elastic band exercise for strengthening muscles on changes in the plantar pressure distribution and the knee space distance of young individuals with genu varum to investigate methods of intervention in effectively managing genu varum. We restructured exercise methods including stretching and elastic band exercise provided by some previous researches to improve knee space width, and applied the adjusted methods to the subjects for four weeks. As a result, the distance in both groups was significantly reduced.

The adductor muscles play a role of producing torque in every movement of the hip joints and generating internal rotation torque (Han, 2009). Shortening of the adductors may increase lateral rotation of the femur to exacerbate 
genu varum. As the hamstring muscles effectively control the locations of the hip and the trunk against the femur, shortening of the hamstring may induce imbalance in stabilizing the hip to damage physical stability. In this context, we applied exercises for extension of the adductors and the hamstring muscles to the stretching group. Meanwhile, the exercise methods using the elastic bands strengthened muscles around the hip joints such as the hip abductors, the gluteus maximus muscles, and the lateral rotators to reduce the knee space width. A stable standing posture does not require considerable muscular activities of the hip joint muscles because static balance is formed between the force of gravity and the extended connective tissues. When the body is swayed by external loads, however, the muscles are strongly contracted to provide more stability. Thus, strengthening of the muscles around the hip joints using elastic bands may increase physical stability more.

During the dynamics of walking, the effect of a genu varum condition has been estimated to cause either an increase in the subtalar joint (STJ) pronation moment or a decrease in the STJ supination moment during the heel loading and propulsion phases of gait. Who walked with genu varum over a force plate and a plantar pressure distribution mat to determine the changes in the ground reaction force vector within the frontal plane and the changes in the center-of-pressure location on the plantar foot (Gheluwe et al., 2005). Most of the subjects in this study used their right feet as the dominant foot, but after the four-week intervention, their plantar pressure was slightly moved from the right to the left feet. The plantar pressure was dispersed from the feet front to the rear, showing patterns of plantar pressure between the front and the rear as well as between the left and the right of the feet. The genu varum deformity would tend to cause a subtalar pronation moment to increase or a supination moment to decrease during the contact and propulsion phases of walking (Gheluwe et al., 2005).

Exercises of correcting genu varum might have positive effects on changes in hip joint angle, Q angle, and knee space distance, and lower limb deformity not by structural causes but by muscular imbalance might be corrected via consistent exercises (Han et al., 2011). Therefore, the genu varum patients in both of the elastic band group and the stretching group showed reduction in the knee space distance, and keeping such exercises may be helpful in correcting the knee space distance. Such results are consistent with those of the existing researches. In addition, correcting the knee space distance by exercises contributed to physical stability to enhance physical balance.

Further studies are needed to identify correlation between genu varum and balance to support the results of this study. Researches of exercise programs for genu varum may improve the quality of life of people with genu varum.

\section{CONCULUSION}

When the genu varum subjects of this study were divided into the stretching group and the elastic band (Thera-band) exercise group for intervention, there were significant changes in the knee space distance. In conclusion, the elastic band exercise and stretching may reduce the knee space distance of people with genu varum to induce physical stability, and these two exercise methods may serve as effective interventions to improve genu varum.

\section{Acknowledgements}

This study is supported by 2015 Research Grant from Kangwon National University (No. 201510108). 


\section{References}

Anderson B, Burke ER. Scientific, medical and practical aspects of stretching. Clin Sports Med. 1991;10:63-86.

Beaulieu JE. Developing a stretching program. Phys Sports Med. 1981;9:59-69.

Chang JS. A biomechanical analysis of lower extremity on the flatfoot with external conditions. Doctor's Degree. Daegu University. 2010.

Gheluwe BV, Kirby KA, Hagman F. Effects of simulated genu valgum and genu varum on ground reaction forces and subtalar joint function during gait. J Amer Podi Med Ass. 2005;95(6):531-41.

Ham YW. Effects of theraband exercise on isotonic strength of flexor muscles in upper extremities. J Health Sci \& Med Tech. 2000;26(1):49-56.

Han SM. A study on the effect of correction exercise on the space between knees of genu varum lower limbs deformation. Master's Degree. Kookmin University. 2009.

Han SM, Lee KK, Ha S, et al. The effects of correction exercise on hip joint angle, $\mathrm{Q}$ angle, and the distance between knees of genu varum patients. Kinesiology. 2011; 13(1):84-6.

Hong JM. The effects of stretching exercises on the difference of flexibility between the sexes of a primary school child. Master's Degree. Daegu National University. 2009.

Jacobson G, Speechley E. Soccer warming up and stretching. J Sports Med. 1990;5(3):17-8.

Kang SH. The effect of rehabilitation programs on bowlegged college student. Doctor's Degree. Keimyung University. 2008.

Kang SH, Lee WJ, Kim TY. Possible effects of applying rehabilitation program upon bowlegged undergraduate COG(Center of Gravity) oscillation its correction. J Sport \& Leisure Studies. 2009;35(2):1061-72.

Karen PC, Michael EB, Bruce MG, et al. Effects of pronated and supinated foot postures on static and dynamic postural stability. J Athl Train. 2005;40(1):41-6.

Kim DS, Choi IS, Kim SY. The impact of lower extremity strengthening exercise with step box and elastic band on balance ability and lower extremity muscular strength in community-living elderly individuals. J Korean Soc Phys Med. 2016;11(1):11-21.

Kim GC, Lee JH, Kwon SM. Effects of hamstring flexibility and dynamic stability of lower lumbar according to stretching and massage techniques. J Korean Soc Phys Med. 2013;8(4):609-17.

Kim JH. The distribution of average plantar pressure in accordance with motion type of foot. Master's Degree. Kyonggi University. 2006.

Kim KS, Lee JS. The effect of chuna manual and taping treatment on genu varum. J Korean Med Rehab. 2010;20(3):93-106.

Kwon KJ. Complete guide for genu varum and arthritis. Seoul. Sam. 2002.

Kwon SY. Effects of elastic band exercise on interval of knee joint, foot pressure and pain for adult women with genu varum according to surface. Master's Degree. Pusan National University. 2013.

Moon MS, Kim I, Kim BK. Treatment of Bowleg. J Korean Orthop Assoc. 1976;11(3):353-62.

Oh SA. The effect of correction exercise with foot orthotics on quadriceps angle and intergonal distance of idiopathic genu vara adolescent. Master's Degree. Korea National Sport University. 2011.

Perry J, Burnfield JM. Gait Analysis: Normal and Pathological Function. U.S.A. Youngmoon. 2012.

Petterson SC, Barrance P, Marmon AR. Time course of quad strength, area, and activation after knee arthroplasty and strength training. Sports Exercise. 2011;43(2): 225-31.

Samaei A, Bakhtiary AH, Elham F, et al. Effects of genu varum deformity on postural stability. Int J Sports Med. 2012;33(06):469-73. 
Smith CA. The warming-up procedure: To stretch or not to stretch a brief review. J Orthop Sports Phys Ther. 1994;19(1):12-7.

Wilkinson A. Stretching the truth. A review of the literature on muscle stretching. Aust Physiother Asso. 1992; 38(4):283-90.

Worrell TW, Smith TL, Winegardener J. Effects of hamstring on hamstring muscle performance. J Orthop Sports
Phys Ther. 1994;20:154-9.

Yamamoto T. Band training and rehabilitation. Japan. Pureunsol. 2000

Yu BK, Kim EH. The effects of the correction exercise program combined with stretching and elastic band exercise on femoral intercondylar distance, Q-angle, plantar pressure in undergraduate with genu varum. J Kore Aca Indus Coope Soc. 2015;16(3):2064-72. 
